\title{
Component and protein domain exchange analysis of a thermoresponsive, two-component regulatory system of Pseudomonas syringae
}

\author{
Correspondence \\ Matthias S. Ullrich \\ m.ullrich@jacobs-university.de
}

Received 23 March 2008

Revised 2 June 2008

Accepted 11 June 2008

\author{
Yvonne Braun, Angela V. Smirnova, Alexander Schenk, Helge Weingart, \\ Claudia Burau, Georgi Muskhelishvili and Matthias S. Ullrich
}

\author{
Jacobs University Bremen, School of Engineering and Science, Research II, Campus Ring 1, 28759 \\ Bremen, Germany
}

\begin{abstract}
Two closely related phytopathogenic bacterial strains, Pseudomonas syringae pv. glycinea PG4180 and $P$. syringae pv. tomato DC3000, produce the chlorosis-inducing phytotoxin coronatine (COR) in a remarkably divergent manner. PG4180 produces COR at the virulencepromoting temperature of $18{ }^{\circ} \mathrm{C}$, but not at $28^{\circ} \mathrm{C}$. In contrast, temperature has no effect on COR synthesis in DC3000. A modified two-component system consisting of the histidine protein kinase (HPK), CorS, the response regulator (RR), CorR, and a third component, CorP, governs COR biosynthesis in both strains. A plasmid-based component and domain swapping approach was used to introduce different combinations of RRs, HPKs and hybrid HPKs into corS mutants of both strains. Subsequently, expression levels of the COR biosynthetic cma operon were determined using RNA dot-blot analysis, suggesting that CorRSP of PG4180 mediates a thermoresponsive phenotype dependent on the genomic background of each strain. The reciprocal experiment demonstrated a loss of temperature dependence in the corS mutant of PG4180. The presence of corR from PG4180 led to more pronounced cma expression in DC3000 and was associated with thermoresponsiveness, while corS of PG4180 did not mediate a temperature-dependent phenotype in the DC3000 mutant containing native cor $R$ and corP. These findings were substantiated by RT-PCR experiments. The C-terminal domain of CorS of PG4180 mediated thermosensing, while the $\mathrm{N}$ terminus did not respond to temperature changes, suggesting cytosolic perception of the temperature signal.
\end{abstract}

\section{INTRODUCTION}

The non-host-specific phytotoxin coronatine (COR) is a virulence factor produced by several pathovars of Pseudomonas syringae that significantly contributes to the development of disease symptoms on infected host plants. COR is produced by $P$. syringae pvs alisalensis, atropurpurea, glycinea, maculicola, morsprunorum, porri and tomato, which infect broccoli, ryegrass, soybean, crucifers, Prunus spp., leek and tomato, respectively (Bender et al., 1989; Cintas et al., 2002; Koike et al., 1999; Mitchell, 1982; Völksch \& Weingart, 1998; Zhao et al., 2002). COR consists of two distinct moieties, the polyketide coronafacic acid (CFA) and a cyclized amino acid, coronamic acid (CMA), which are synthesized independently and fused by amide bond linkage (Mitchell et al., 1994; Parry et al., 1994).

$P$. syringae $\mathrm{pv}$. glycinea PG4180 produces COR in a strongly temperature-dependent manner, with maximum

Abbreviations: CFA, coronafacic acid; CMA, coronamic acid; COR, coronatine; HPK, histidine protein kinase; RR, response regulator; TCS, two-component system. synthesis at $18{ }^{\circ} \mathrm{C}$ and negligible synthesis at $28{ }^{\circ} \mathrm{C}$, which is the optimal growth temperature of the bacterium (Budde et al., 1998; Palmer \& Bender, 1993). In PG4180, enzymes involved in COR biosynthesis are encoded on a plasmidborne $32 \mathrm{~kb}$ DNA region which has been characterized extensively (Bender et al., 1993; Liyanage et al., 1995a, b; Ullrich \& Bender, 1994; Ullrich et al., 1995). Two biosynthetic operons, required for synthesis of CMA and $\mathrm{CFA}$, respectively, and a $3.4 \mathrm{~kb}$ regulatory region encoding a modified two-component system (TCS) were identified (Couch et al., 2004; Rangaswamy et al., 1998; Ullrich \& Bender, 1994; Bender et al., 1996) (Fig. 1). Transcriptional fusions of a promoterless $\beta$-glucuronidase (uidA) gene to promoter regions of both operons showed maximal activity at $18{ }^{\circ} \mathrm{C}$, indicating that COR biosynthesis in PG4180 is regulated by temperature at the transcriptional level (Budde et al., 1998; Liyanage et al., 1995b; Ullrich et al., 1995).

The CorRSP regulatory system is composed of the histidine protein kinase (HPK), CorS, the response regulator (RR), CorR and a third component, termed CorP. Insertional 


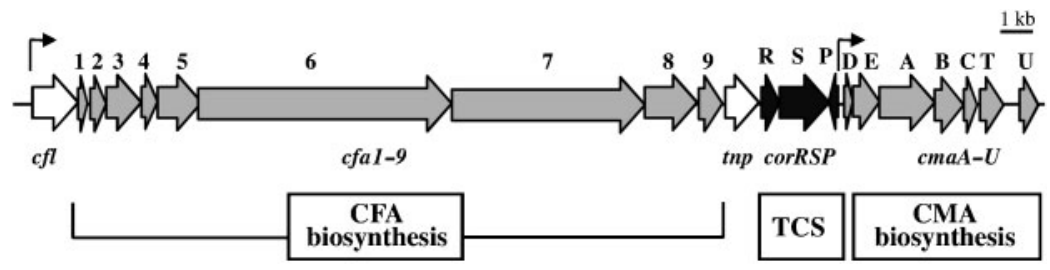

Fig. 1. Functional map of the COR biosyn-
thetic gene cluster of PG 4180 showing DNA
regions required for CFA and CMA biosyn-
thesis, respectively, and for transcriptional
regulation. Arrows indicate thermoresponsive
$c f l$ and cma promoter regions.

mutations in $\operatorname{cor} R$, corS and $\operatorname{cor} P$, respectively, completely abolished transcriptional activation of COR biosynthetic promoters (Bender et al., 1993; Ullrich et al., 1995). Moreover, a $3.4 \mathrm{~kb}$ DNA fragment containing corRSP restored temperature-regulated transcriptional activation of the COR biosynthetic promoters and COR production in the respective mutants (Ullrich et al., 1995). CorS is believed to respond to a temperature change via autophosphorylation of a conserved histidine residue, followed by transduction of the signal to CorR via phosphorylation of its conserved aspartate residue (Rangaswamy \& Bender, 2000). A conserved helix-turn-helix DNA-binding motif was identified in CorR, which binds to DNA upstream of both biosynthetic operons, while CorP lacks such a motif (Peñaloza-Vázquez \& Bender, 1998; Wang et al., 1999). Overproduction of CorR in a corS mutant background of PG4180 or at $28{ }^{\circ} \mathrm{C}$ resulted in an inactive protein in DNAbinding assays (Wang et al., 1999), highlighting the importance of a functional CorS.

According to topology prediction and reporter enzyme fusion assays (Smirnova \& Ullrich, 2004), the $\mathrm{N}$ terminus of CorS contains six transmembrane domains, whereas the $\mathrm{C}$ terminus is located in the cytosol. CorS contains typical histidine kinase domains: a dimerization and histidine phosphotransfer domain and a conserved catalytic and ATP-binding domain (CA). A conserved histidine residue (His-254) located in the H-box of CorS is the presumptive site of autophosphorylation. The CA domain of CorS consists of other conserved HPK motifs, such as the N-, D-, F- and G-boxes, which are involved in ATP-binding, catalysis and phosphotransfer (Grebe \& Stock, 1999).

The $P$. syringae pv. tomato DC3000 genome sequencing project (http://pseudomonas-syringae.org/pst_home.html) has allowed a comparative analysis of genes involved in regulation of COR biosynthesis. Genes encoding CorRSP are present in the DC3000 genome (Brooks et al., 2004). However, in DC3000 the corRSP genes map with the CMA structural genes and are separated from the CFA structural genes by a $26 \mathrm{~kb}$ DNA region (Buell et al., 2003; Sreedharan et al., 2006). DC3000 produces significantly less COR than PG4180 in vitro, and temperature does not affect COR biosynthesis.

Recently, Smirnova et al. (2008) conducted site-directed mutagenesis of corS from PG4180 in order to convert its gene product into a non-temperature-responsive derivate, like CorS of DC3000. Either inactive enzyme variants or even more thermoresponsive ones were obtained, but no clear conversion of phenotype could be accomplished. These results indicated that single or combined amino acyl residue changes easily disturb the complex character of a membrane-bound HPK. Consequently, a novel strategy was approached in the present paper.

Herein, a corRS mutant of DC3000 was constructed to assess the role of HPK and RR in regulation of COR production in DC3000. By exchanging the respective TCS components between PG4180 and DC3000 in a plasmidborne complementation assay with corRS mutants of either strain, differences in the regulatory function of CorS were investigated. Furthermore, CorS hybrids derived from PG4180 and DC3000 were generated to analyse the role of the membrane-embedded $\mathrm{N}$ terminus and the cytosolic $\mathrm{C}$ terminus of this HPK for thermosensing.

\section{METHODS}

Bacterial strains, plasmids and growth conditions. The bacterial strains used in this study are listed in Table 1 . Plasmids are listed in Table 2. Escherichia coli cells were grown at $37^{\circ} \mathrm{C}$ in Luria-Bertani (LB) medium. $P$. syringae cells were maintained at $28{ }^{\circ} \mathrm{C}$ on Mannitol-Glutamate (MG) medium (Keane et al., 1970). For liquid cultures, $P$. syringae cells were grown at 18 and $28{ }^{\circ} \mathrm{C}$ at 280 r.p.m. in Hoitink-Sinden medium optimized for COR production (HSC) (Palmer \& Bender, 1993). Antibiotics were used at the following concentrations: ampicillin (Ap, $100 \mu \mathrm{g} \mathrm{ml}^{-1}$ ), kanamycin (Km, $\left.25 \mu \mathrm{g} \mathrm{ml}^{-1}\right)$, tetracycline $\left(25 \mu \mathrm{g} \mathrm{ml}^{-1}\right)$.

Construction of the corRS mutant DC3000.M1. Unless otherwise indicated, standard methods were performed according to Sambrook \& Russell (2001). Marker exchange mutagenesis was used to generate a knockout mutant of corS in P. syringae DC3000. Two fragments, each of which contained sequences adjacent to corS, were PCR-amplified from the genomic DNA of DC3000. Using primers out_FcorS (5'-CTAGTCTAGATGTAATGCGGAAAAACGCCT- $\left.3^{\prime}\right)$ and in_RcorS (5'CCAGAATTCTGAGTTCGACCAGAATGAGT- $\left.3^{\prime}\right)$, a $1.4 \mathrm{~kb} \quad$ XbaIEcoRI fragment was amplified, and using primers in_FcorS (5'CCGGAATTCCCGTTTTAGCGCACCTCAAC-3') and out_RcorS (5' CAAGGTACCGGTACAAACGTTCGTGGCCA-3') a $1.6 \mathrm{~kb}$ EcoRI$K p n \mathrm{I}$ fragment was amplified, and subsequently ligated to pBluescript, yielding plasmid pBSXK30. A $1.7 \mathrm{~kb} \mathrm{Km}$ cassette from pMKm (Murillo et al., 1994) was inserted into a unique EcoRI site of pBSXK30, yielding the suicide vector pBSXB47, which was mobilized into DC3000 by electroporation followed by screening for $\mathrm{Ap}^{\mathrm{s}} \mathrm{Km}^{\mathrm{r}}$ derivatives. Recombination of the $\mathrm{Km}$ cassette into genomic corS was verified by Southern blot analysis and PCR using primers corS_fwd_DC3000 (5' GGAATTCCGGATAGACTCAATTAAT-3') and corS_rev_DC3000 (5' GGAATTCAGGTATACGTAGTCCATG-3').

Construction of plasmid-borne TCS exchange systems. First, a plasmid-based system containing corRSP was created, which enabled 
Table 1. Bacterial strains used in this study

\begin{tabular}{|c|c|c|}
\hline Bacterial strain & Relevant characteristics ${ }^{\star}$ & Reference \\
\hline \multicolumn{3}{|l|}{ Escherichia coli } \\
\hline $\mathrm{DH} 5 \alpha$ & 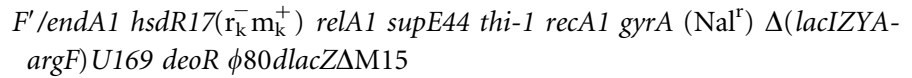 & Sambrook \& Russell (2001) \\
\hline HB101 & $\begin{array}{l}F^{-} \Delta(\text { gpt-proA }) 62 \text { leuB6 supE44 ara-14 galK2 lacY1 } \Delta(m r c C-m r r) \text { rpsL20 } \\
\left(\mathrm{Sm}^{\mathrm{r}}\right) \text { xyl-5 mtl-1 recA13 }\end{array}$ & Sambrook \& Russell (2001) \\
\hline \multicolumn{3}{|c|}{ P. syringae pv. glycinea } \\
\hline PG4180 & $\mathrm{COR}^{+} \mathrm{CFA}^{+} \mathrm{CMA}^{+}$ & Mitchell (1982) \\
\hline PG4180.D4 & corR: $: \operatorname{Tn} 5 ; \mathrm{Km}^{\mathrm{r}} \operatorname{cor} R^{-} \operatorname{corS}^{-}$ & Bender et al. (1993) \\
\hline \multicolumn{3}{|c|}{ P. syringae pv. tomato } \\
\hline DC3000 & Derivative of NCPPB1106, $\mathrm{Rf}^{\mathrm{r}}$ & Cuppels (1986) \\
\hline DC3000.M1 & $\mathrm{Km}^{\mathrm{r}} \operatorname{cor} S^{-}$ & This study \\
\hline
\end{tabular}

*Abbreviations: Km, kanamycin; Nal, nalidixic acid; Rf, rifampicin; Sm, streptomycin.

us to remove the corS gene of PG4180 and substitute it with corS from DC3000 or hybrid-corS (Fig. 2). corRSP from PG4180 were amplified as a $3.4 \mathrm{~kb}$ PCR product using primers T3HindIII $\left(5^{\prime}-\right.$ GGCAAGCTTATTAACCCTCACTAAAG-3') and T7HindIII (5'GACAAGCTTAATACGACTCACTATAG- $3^{\prime}$ ), and subsequently ligated into pRK415, resulting in plasmid pASH34. To generate a construct with unique restriction sites upstream and downstream of corS and within non-coding regions, three PCR fragments were amplified using pASH34 as template. The following primers were used: for corR, T7HindIII (5'-GACAAGCTTAATACGACTCACTATAG-3') and corRSpeI_rev (5'-GTCGTGCCTCACAGGACTAGTCCTAGGCGGCGCGCGGCA-3 $\left.{ }^{\prime}\right)$; for cors, corSSpeI_fwd ( $5^{\prime}$ ATGCCGCGCGCCGCCTAGGACTAGTCCTGTGAGGCACG-3') and corSXbaI_rev (5' -TGAAAGGTACTAACGGTCTAGAAGGCATTGCCTTGCTG-3); for corP, corPXbaI_fwd (5' -CAGCAAGGCGATGCCTTCTAGACCGTTAGTACCTTTCA- $3^{\prime}$ ) and T3HindIII (5'-GGCAAGCTTATTAACCCTCACTAAAG- $3^{\prime}$ ). The $1.4 \mathrm{~kb}$ amplification product containing corR was digested with SpeI and HindIII and ligated to similarly treated pBluescript II SK, yielding pHS14. A $1.5 \mathrm{~kb}$ PCR product containing corS was treated with $\mathrm{SpeI}$ and $\mathrm{Xba \textrm {I }}$ and ligated into similarly treated pHS14 to give pHX29. A $0.5 \mathrm{~kb}$ PCR product containing $\operatorname{corP}$ was treated with $\mathrm{Xba \textrm {I }}$ and ligated into $\mathrm{XbaI}$-treated pHX29 to give pHX34. The $3.4 \mathrm{~kb}$ fragment containing corRSP was subcloned into pRK415 using EcoRI. The thereby generated plasmid, pASE34 (Fig. 2), was analogous to pMUH34 (Ullrich et al., 1995), but contained SpeI and $\mathrm{XbaI}$ restriction sites upstream and downstream of corS, respectively. The PCR products used to construct pASE34 were verified by nucleotide sequencing. Colony PCR was used to amplify a $1.5 \mathrm{~kb}$ SpeI-XbaI fragment comprising corS from DC3000. The PG4180 corS was excised as a $1.5 \mathrm{~kb}$ SpeI-XbaI fragment from pASE34 and was replaced by the DC3000 corS to yield pASE34D.

Hybrid corS genes were constructed by fusion of the $\mathrm{N}$ and $\mathrm{C}$ termini of corS from PG4180 and DC3000, respectively. For the N terminus, the sequence encoding all transmembrane domains was PCRamplified $(0.6 \mathrm{~kb})$ with primers corSSpeI_fwd and SRN-terminus (5'-CAATCGGCAGAGCCCCAAGCCGTAAAGCAGCAC-3'). The C terminus, consisting of the cytosol-located catalytic domains $(1.2 \mathrm{~kb})$, was amplified using primer SFC-terminus ( $5^{\prime}$-GTGCTGCTTTACGGCTTGGGGCTCTGCCGATTG-3') and corSXbaI_rev. Subsequently, one $\mathrm{N}$ terminus and one $\mathrm{C}$ terminus were used as templates in a PCR with primers corSSpeI_fwd and corSXbaI_rev. Primers SRN-terminus and SFC-terminus have homologous sequences, therefore PCR products of the $\mathrm{N}$ and $\mathrm{C}$ terminus will align, resulting in corS gene hybrids when amplified with the outer primers corSSpeI_fwd and corSXbaI_rev. PCR products were ligated into pGEM-T Easy and confirmed by nucleotide sequencing. The corS gene hybrids were cloned instead of the native corS genes into the pRK415-based exchange constructs pASE34 and pASE34:D respectively. Resulting plasmids were then mobilized into $P$. syringae by triparental mating with the helper plasmid pRK2013 (Figurski \& Helinski, 1979).

To generate a CorRSP exchange system which contains corRSP from DC3000 with unique restriction sites, plasmid pYBH34 was constructed. Using colony PCR, corR, corS and corP from DC3000 were amplified. Restriction sites upstream and downstream of the respective genes were introduced via primers. For corR, corRHindIII_fwd (5'-GAACATGCTGGGCGCAAGCTTATTTGGCAG-3') and corRSpeI_rev (5'-GTCGTGCCTCACAGGACTAGTCCTAGGCGGCGCGCGGCA-3'); for corS, corSSpeI_fwd (5'-ATGCCGCGCGCCGCCTAGGACTAGTCCTGTGAGGCACG-3') and corSXbaI_rev (5'-TGAAAGGTACTAACGGTCTAGAAGGCATTGCCTTGCTG- $3^{\prime}$ ); and for corP, corPXbaI_fwd (5'-TTGCAAGGCTATGCCTTCTAGACCGTGAGTACC- $3^{\prime}$ ) and corPSacII_rev (5' ${ }^{\prime}$-CCGCGGGCTCTAGGTCCAGGTTTAGTGTGAACA-3') were used. PCR products of $\operatorname{cor} R(1.0 \mathrm{~kb})$ and $\operatorname{cor} S(1.8 \mathrm{~kb})$ were used as templates in a subsequent PCR with primers corRHindIII_fwd and corSXbaI_rev. The $2.8 \mathrm{~kb}$ corRS PCR product as well as the corP PCR product $(0.7 \mathrm{~kb})$ were ligated into pGEM-T Easy, yielding plasmids pGEM : corRS and pGEM : corP, which were confirmed by sequencing. Subsequently, $\operatorname{cor} P$ was transferred into pGEM : corRS using $X b a \mathrm{I}$ and SacII. The resulting construct $(3.5 \mathrm{~kb})$, designated pGEM : corRSP, contained all three genes of the TCS from DC3000 which were subsequently transferred to vector pBluescript II SK, yielding $\mathrm{pB}$ corRSP-DC. In this vector, exchange of corS from DC3000 against recombinant corS from PG4180 and hybrid-corS sequences was carried out. Plasmid pBcorRSP-DC was digested with SpeI and XbaI to remove cors. The remaining $\mathrm{pB}$ corRP-DC was purified. Subsequently, SpeI/XbaI-treated recombinant or hybrid-corS was ligated with $\mathrm{pB}$ corRP-DC. The resulting constructs (Table 2) were mobilized into $P$. syringae by triparental mating.

RNA dot-blot analysis. Bacteria were grown in HSC medium at 18 and $28{ }^{\circ} \mathrm{C}$ until an $\mathrm{OD}_{600}$ of $1.3-1.5$ was reached. Total RNA was isolated by acid phenol/chloroform extraction as described by Schenk et al. (2008). Aliquots of total RNA (200 ng per dot) were transferred to positively charged nylon membranes (Pall) using the Minifold I Spot-Blot System (Schleicher \& Schuell), according to the manufacturer's recommendations. The digoxigenin-labelled specific RNA probes were synthesized by in vitro transcription using T7 RNA polymerase and specific PCR products as templates. PCR amplification of the cma template was performed using primers cmaA-fwd 
Table 2. Plasmids used in this study

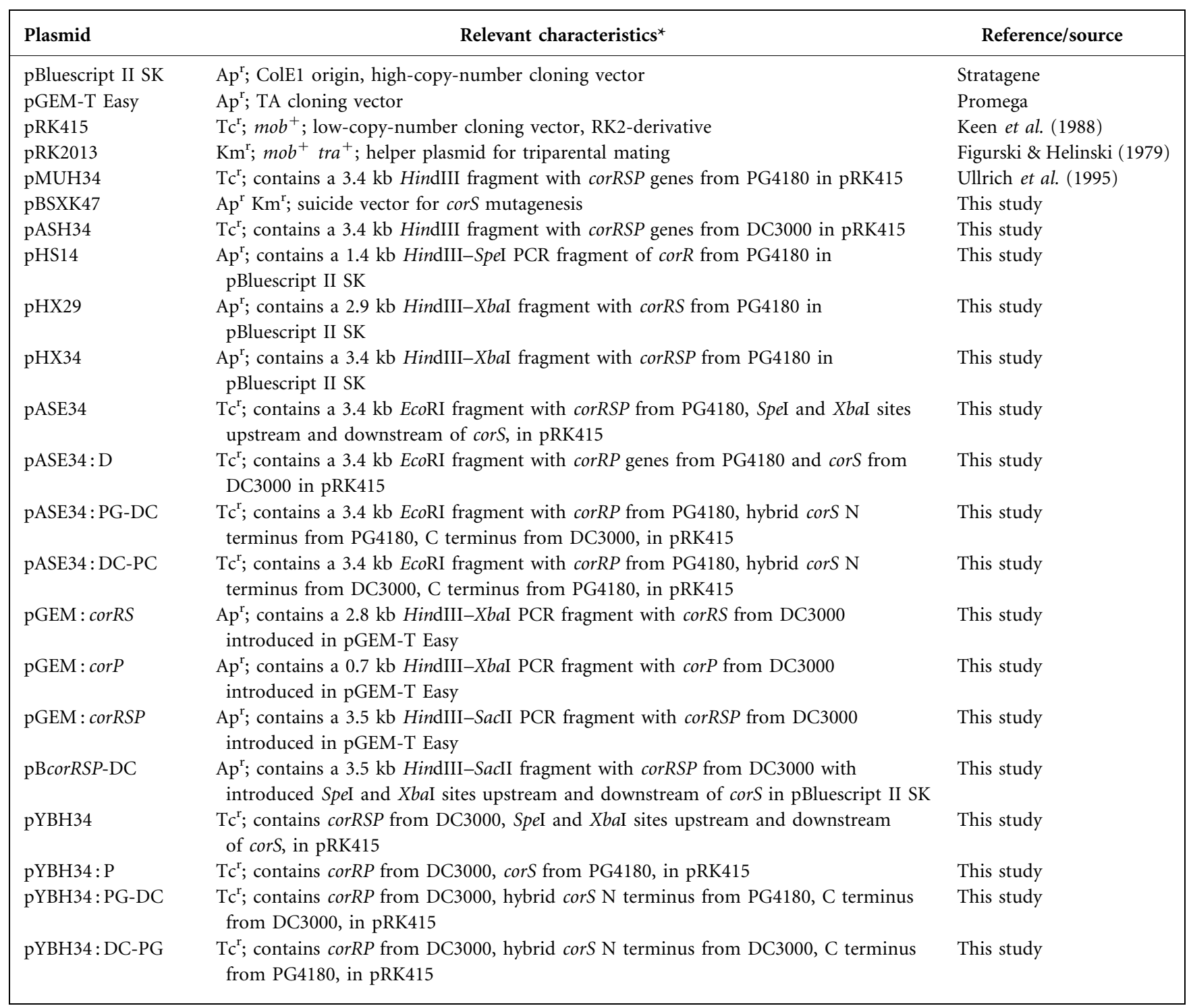

*Abbreviations: Ap, ampicillin; Km, kanamycin; Sm, streptomycin; Sp, spectinomycin; Tc, tetracycline; mob, mobilization function; tra, transfer function.

(5'-TTTGAGTCGGTCTGCACGCA-3') and cmaA-revT7 (5' ${ }^{\prime}$-TAATACGACTCACTATAGGGAGGGCTGTACGTTGTCTACTAG-3'). For the synthesis of DIG-labelled RNA probes, the Strip-EZ RNA Probe Synthesis and Removal kit (Ambion Europe) and digoxigenin-11-UTP (Roche Diagnostics) were used. The probe was hybridized to the membrane in hybridization solution $(50 \%$ formamide, $7 \%$ SDS, $2 \%$ blocking reagent, $0.1 \% \mathrm{~N}$-laurylsarcosine, $5 \times \mathrm{SSC}$ ) at $68{ }^{\circ} \mathrm{C}$ for $16 \mathrm{~h}$. After hybridization, the membrane was washed twice for $5 \mathrm{~min}$ at room temperature in $2 \times$ SSC containing $0.1 \%$ SDS, followed by two washes for $15 \mathrm{~min}$ at $68{ }^{\circ} \mathrm{C}$ in $0.2 \times$ SSC containing $0.1 \%$ SDS. Hybridization signals were detected by incubation with anti-digoxigenin-AP Fab fragments (Roche Diagnostics) and a fluorescence substrate for alkaline phosphatase (ECF) (Amersham-Pharmacia Biotech) using an FLA-3000 phosphoimager (Raytest). Signals were quantified using the AIDA Image Analyser software package (Raytest).
RT-PCR analysis of $\mathbf{c m a}$ and corR expression. Bacterial cells were grown and total RNA was extracted as described above. RNA samples were treated with an excess of RNase-free DNase (Ambion). The oligonucleotides used to amplify cma and corR signals were: cmaA_RT_fw (5' ${ }^{\prime}$-CCTACCGCCGATTTGAGT-3'), cmaA_RT-rev (5'-CCAGGCCTTGACGTATCAGT-3'), corR_RT_fw (5' -ATGCCGAGCTCTTCGATCT- $\left.3^{\prime}\right)$, corR_PG_rev (5'-AGACGCCTCCTCGATCCT-3') and corR_DC_rev (5'-AAGCGCCTGCTCGATCCT-3' ${ }^{\prime}$. QuantiTect SYBR Green one-step RT-PCRs were performed in triplicate, following the manufacturer's instructions (Qiagen), and using an Mx3000P Real-time cycler instrument (Stratagene). Reactions in which reverse transcriptase was omitted served as negative controls and demonstrated the lack of DNA contamination.

Extraction and quantification of COR. Organic acids were extracted from cell-free bacterial supernatants $(1.5 \mathrm{ml})$ and analysed 
(a)

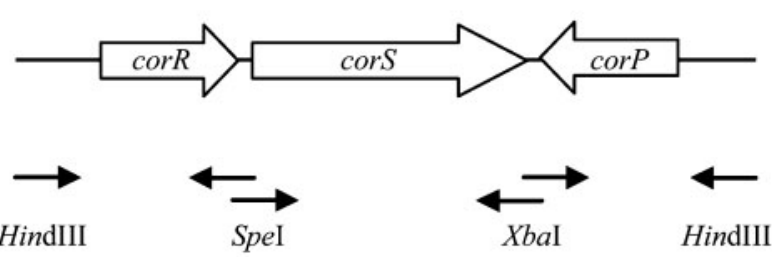

(b)

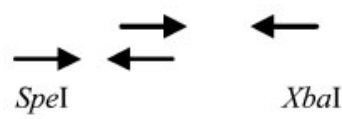

(c)

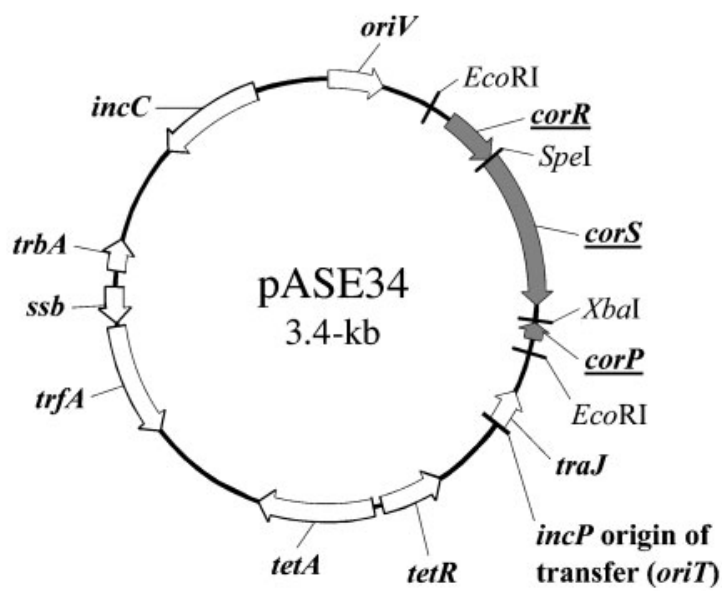

Fig. 2. Construction of the TCS-Exchange system illustrated for PG4180. (a) Primer-binding sites (thin arrows) with introduced restriction sites for the generation of three PCR products which were fused to construct the system. Genes encoding CorRSP are represented by large arrows. (b) Primer-binding sites for amplification of the $\mathrm{N}$ and $\mathrm{C}$ termini of CorS which were fused to generate CorS hybrids. (c) Broad-host-range plasmid containing the final recombinant TCS for introduction into $P$. syringae.

for the presence of COR by high-pressure liquid chromatography (HPLC) as described by Budde et al. (1998). Bacterial cell pellets were used to determine total protein content according to Bradford (1976).

\section{RESULTS}

\section{Expression levels of $\mathrm{cma}$ and complementation of PG4180, DC3000 and respective corRS mutants}

PG4180 had previously been characterized as temperaturedependent with regard to COR biosynthesis and promoter activity of COR biosynthetic genes (Ullrich et al., 1995). In contrast, temperature had little or no effect on DC3000 in vitro. In this study, cmaA mRNA levels at 18 and $28{ }^{\circ} \mathrm{C}$ were quantified in PG4180, DC3000 and corRS mutants of both strains (Fig. 3). In PG4180, wild-type cma expression was 20 -fold higher at 18 compared to $28{ }^{\circ} \mathrm{C}$. The respective corRS mutant, PG4180.D4, displayed only basal low levels of

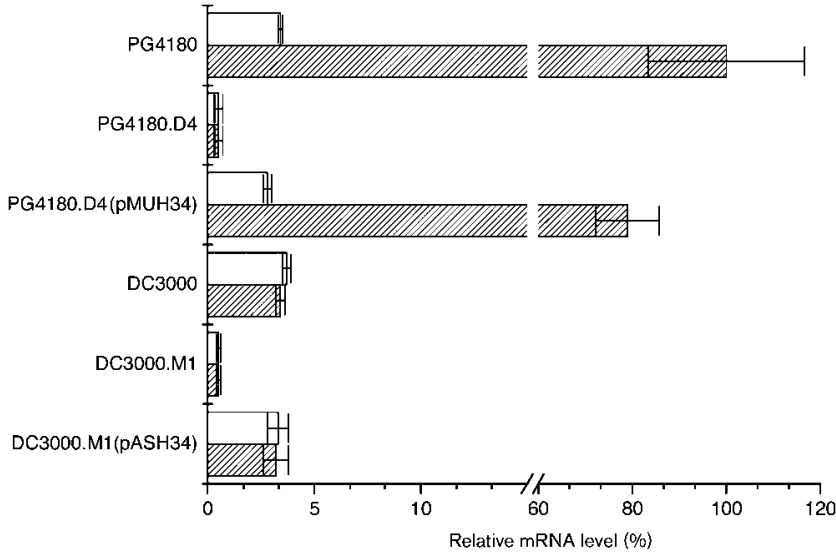

Fig. 3. Expression of $\mathrm{cma}$ at 18 (hatched bars) and $28{ }^{\circ} \mathrm{C}$ (white bars) in $P$. syringae strains PG4180, DC3000, PG4180.D4 and DC3000.M1, and complemented mutants. Quantities represent means of two experiments with six replicates. The cma expression at $18{ }^{\circ} \mathrm{C}$ in PG4180 represents $100 \%$. Error bars represent the $\mathrm{SD}$ from the means $(n=12, P<0.005)$.

cma expression at both temperatures. Plasmid pMUH34, containing corRSP from PG4180, restored temperaturedependent $c m a$ expression to this mutant, demonstrating that PG4180.D4 could be fully complemented. In contrast, temperature had virtually no effect on $\mathrm{cma}$ expression in DC3000. Moreover, DC3000 displayed much lower cma expression at $18{ }^{\circ} \mathrm{C}$ compared to PG4180. At $28{ }^{\circ} \mathrm{C}$, both strains showed comparable cma expression levels. Subsequently, cma mRNA abundance was quantified in the corRS mutant DC3000.M1. Transcription of cma was completely abolished at both temperatures (Fig. 3), suggesting that transcriptional activation of COR biosynthetic genes was corRS-dependent in DC3000. Not surprisingly, neither mutant DC3000.M1 nor mutant PG4180.D4 produced any detectable amounts of COR, regardless of temperature, in contrast to the wild-type strains (data not shown; Ullrich et al., 1995; Smirnova et al., 2008).

Previous results revealed that a $3.4 \mathrm{~kb}$ fragment containing corRSP from PG4180 is sufficient to complement mutations in these regulatory genes with respect to COR production and activity of COR biosynthetic promoters (Ullrich et al., 1995). To achieve complementation of DC3000.M1, we constructed plasmid pASH34 carrying a $3.4 \mathrm{~kb}$ fragment containing the three regulatory genes of DC3000. In DC3000.M1(pASH34), equal levels of COR and $c m a$ mRNA were detected at 18 and $28{ }^{\circ} \mathrm{C}$, comparable to those of the wild-type (Fig. 3 and data not shown), suggesting that recombinant corRSP successfully complemented the mutant and were required and sufficient for cma expression in DC3000.

\section{Analysis of TCS exchange systems}

CorRSP regulate COR production in strains PG4180 and DC3000, despite the obvious differences in thermorespon- 
siveness (Weingart et al., 2004). The specific role(s) of individual CorRSP components and CorS domains in thermosensing for COR gene expression were investigated using recombinant CorRSP exchange systems. Constructs with different combinations of CorRSP and CorS hybrids from PG4180 and DC3000 were analysed with respect to cma mRNA synthesis in corRS mutants of either strain at 18 and $28{ }^{\circ} \mathrm{C}$, respectively (Fig. 4). Three major results obtained from these analyses allowed us to draw the following conclusions.

First, regardless of the mutant background, any combination with corR and corP from DC3000 yielded low or almost negligible cma expression, suggesting that CorR of DC3000 is either not properly expressed or barely active under the tested conditions. In contrast, any combination with corR and corP from PG4180 gave rise to significant cma expression, indicating that CorR of PG4180 was functional.

Second, a clear thermoresponsive activity of CorRSP associated with significantly high $\mathrm{cma}$ expression was only obtained when CorR of PG4180 was combined with its cognate CorS or the CorS hybrid containing the C terminus derived from PG4180, suggesting that the molecular interplay of CorR and the $\mathrm{C}$ terminus of CorS might be essential for temperature-mediated cma expression. However, this interaction additionally seemed to depend on the cellular background, since a combination of PG4180-derived CorR with its cognate CorS or a CorS hybrid containing a PG4180-based C terminus remained non-thermoresponsive in the DC3000 mutant.

Third, very puzzling results were obtained when $\operatorname{cor} R$ and corP from PG4180 were combined with corS of DC3000: while this construct yielded moderate cma expression in the PG4180 mutant regardless of temperature, it showed moderate but thermoresponsive cma expression in the DC3000 background. Consequently, the construct was generated de novo and the analyses were repeated several times, each time giving the same inconclusive combination of results. Similarly unclear was the finding that the $\mathrm{C}$ terminus of CorS of DC3000 in combination with the N terminus of CorS of PG4180 and CorRP from PG4180 yielded low but still thermoresponsive cma expression. After generating this construct again, similar results were obtained. These inconsistencies prompted us to conduct confirmatory RT-PCR experiments with some of the exchange constructs.

\section{RT-PCR analysis with selected TCS exchange constructs}

To substantiate the main results of the RNA dot-blot analyses, RT-PCR experiments were performed with six of the TCS exchange constructs harbouring different combinations of CorRSP and CorS hybrids from PG4180 or DC3000. Samples were analysed with respect to $\mathrm{cma}$ and corR mRNA synthesis in corRS mutants of either strain at 18 and $28{ }^{\circ} \mathrm{C}$, respectively (Fig. 5). As expected, the presence of corRSP from PG4180 and from DC3000 resulted in strong thermoresponsive cma expression versus low level temperature-independent cma expression, respectively. Whenever corRP were derived from DC3000, a low level of expression of $c m a$ was detected, while corRP from PG4180 resulted in higher levels of expression, thus confirming the RNA dot-blot results. The analysis of the construct, in which CorRP and the $\mathrm{N}$ terminus of CorS from PG4180 were combined with the C terminus of CorS derived from DC3000 and expressed in PG4180.D4, did not confirm the low-level but thermoresponsive result of

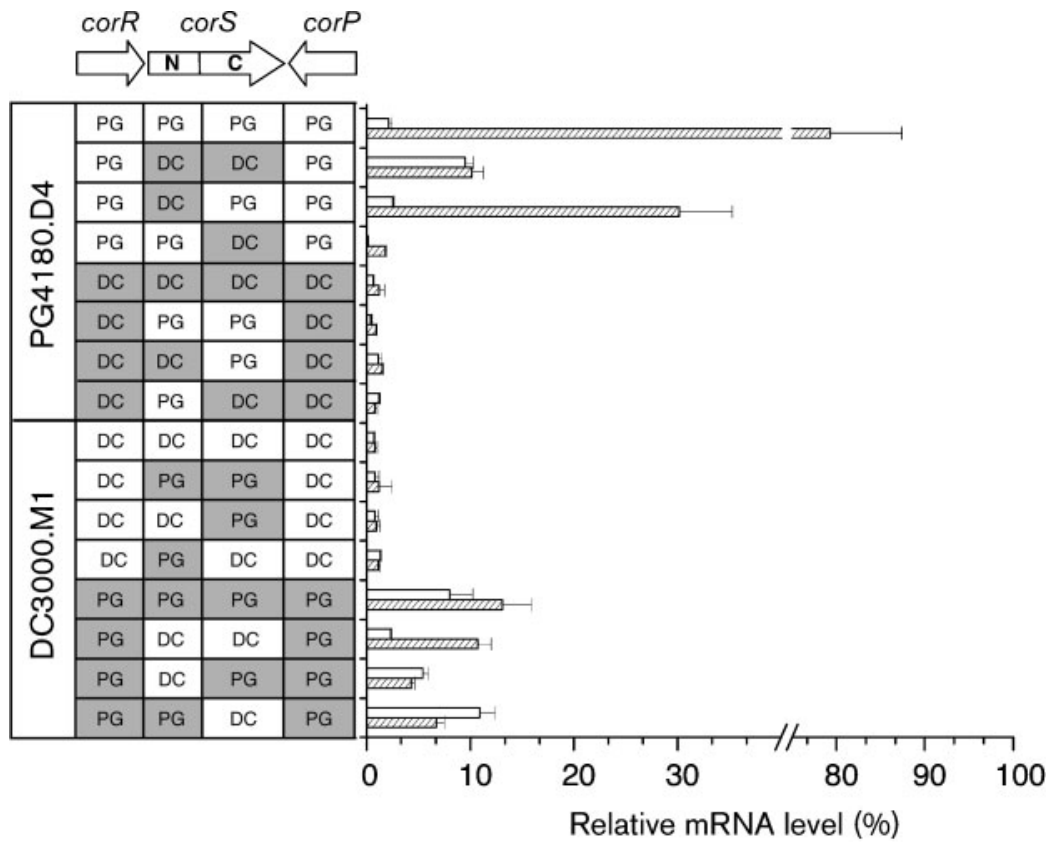

Fig. 4. Expression of $\mathrm{cma}$ at 18 (hatched bars) and $28{ }^{\circ} \mathrm{C}$ (white bars) in $P$. syringae strains PG4180.D4 and DC3000.M1 harbouring CorRSP exchange plasmids. The table summarizes the recombinant systems: grey boxes represent non-native genes or nonnative parts of genes. PG, PG4180-derived components or domains; DC, DC3000derived components or domains. Quantities represent means of two experiments with six replicates. The relative mRNA level is relative to the level of cma mRNA synthesized at $18^{\circ} \mathrm{C}$ in PG4180, which was defined as $100 \%$. Error bars represent the SD from the means $(n=12, P<0.005)$. 


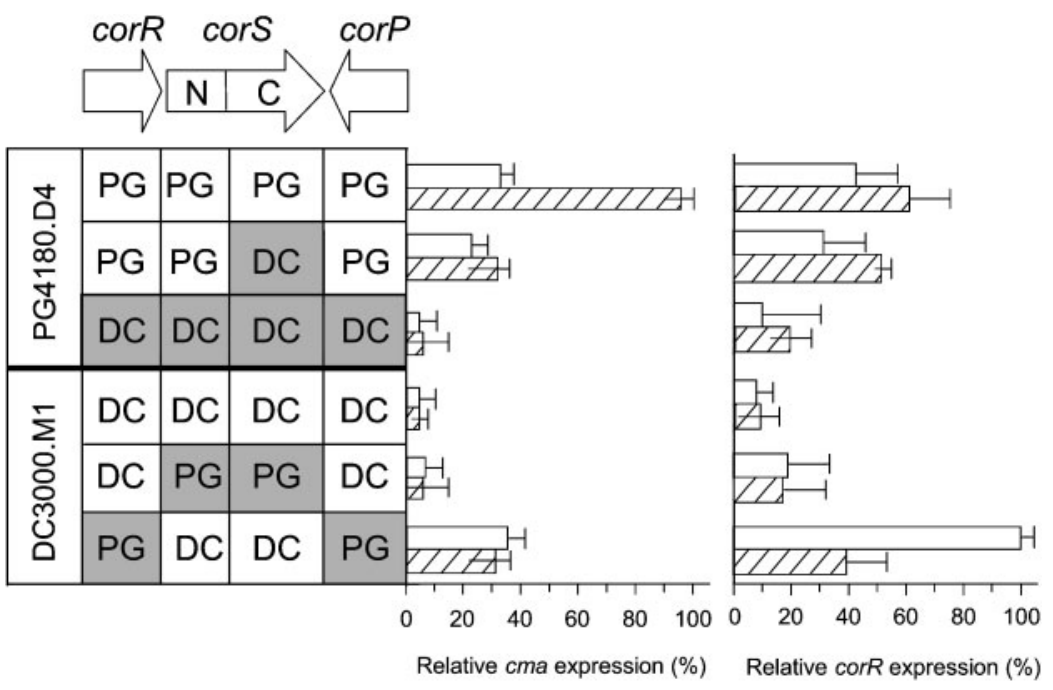

Fig. 5. RT-PCR analyses for the expression of cma and corR with selected TCS exchange constructs at 18 (hatched bars) and $28^{\circ} \mathrm{C}$ (white bars). The table summarizes the recombinant systems: grey boxes represent nonnative genes or non-native parts of genes. PG, PG4180-derived components or domains; DC, DC3000-derived components or domains. Quantities represent means of three experiments with four replicates. Relative expression levels are related to the level of the highest signals, which were defined as $100 \%$. Error bars represent the SD from the means $(n=12, P<0.005)$. this construct derived from RNA dot-blot analysis (Fig. 5). Also, in contrast to the above results, thermoresponsive cma expression of the construct with CorRP from PG4180 and CorS from DC3000 present in DC3000.M1 was moderate but temperature-independent.

The analysis of corR expression using RT-PCR revealed that corR of PG4180 is generally more highly expressed compared to its homologue from DC3000, regardless of the genomic background of the mutants (Fig. 5). No statistically significant temperature dependence of corR expression was observed except in one case, where corRP from PG4180 were combined with corS from DC3000 and tested in mutant DC3000.M1.

\section{DISCUSSION}

Results of this study regarding strain-specific differences in temperature-dependent $\mathrm{cma}$ expression in $P$. syringae substantiated our earlier findings (Weingart et al., 2004) and demonstrated that the frequently used $P$. syringae strain DC3000 does not produce significant amounts of the phytotoxin in vitro. Previously, transcriptional fusions of the cma promoter to an egfp reporter gene were monitored in vitro and in planta (Weingart et al., 2004), suggesting that cma promoter activity in DC3000 was plant-inducible, while in PG4180 it was temperature-dependent regardless of any plant-borne signals.

COR production and cma expression were completely abolished in strain DC3000 when corRS were knocked out, indicating a vital role of these genes for phytotoxin regulation. Unexpectedly, cross-complementation of the corRS mutant of DC3000 with corRSP derived from PG4180 did not result in thermoresponsiveness of cma expression, suggesting that the genomic background of DC3000 dictates either corR expression or CorR activity and, consequently, transcription of the cma operon. In contrast, the genetic background of PG4180 did not render the regulatory triad of DC3000 thermoresponsive, indicating that thermosensing requires both indigenous CorRSP and the genetic background of PG4180. In this respect, RNA dot-blot results were confirmed by RT-PCR analysis and may reflect evolutionary adaptations of either pathovar, i.e. pv. glycinea (PG4180) on soybeans and pv. tomato (DC3000) on tomato and Arabidopsis, to their host plants. The cold-weather pathogen, PG4180, might sense abiotic parameters such as temperature (Budde et al., 1998) while strain DC3000 might respond directly to plant signals (Weingart et al., 2004).

The expression of corR was investigated in selected TCS exchange constructs using RT-PCR. The results suggest that corR expression in all but one case is not thermoresponsive, and indicate that temperature sensing is restricted to CorS activity. This result is not surprising, since regulatory genes are not usually expressed at a high level. Why corR expression was thermoresponsive and unusually high in DC3000.M1 harbouring CorRP from PG4180 and CorS from DC3000 remains to be investigated in future studies.

Interestingly, upstream of the DC3000 corR gene, a binding site for the alternative sigma factor, HrpL, responsible for expression of the hrp operon encoding a type III secretion system, was found (Fouts et al., 2002). An hrpL mutant of DC3000 was significantly impaired in expression of corR (Sreedharan et al., 2006). Additionally, a putative corR binding site was identified upstream of $h r p L$, demonstrating an interconnection of the expression of these two regulatory proteins in DC3000 (Sreedharan et al., 2006). In this context it is noteworthy that PG4180 does not possess a recognizable $h r p$-box upstream of its corR gene (data not shown).

Besides the activity of CorRSP, COR synthesis in PG4180 and DC3000 seems to be governed by the alternative sigma factor RpoN $\left(\sigma^{54}\right)$ (Alarcon-Chaidez et al., 2003). $\sigma^{54}$ is required for a number of metabolic functions, including 
utilization of alternative carbon and nitrogen sources, nitrogen fixation, and expression of virulence genes (Kustu et al., 1989; Studholme \& Buck, 2000; Wösten, 1998). Thus, a combination of regulatory pathways governed by $\sigma^{54}$ and CorRSP may lead to responsiveness of COR production to various abiotic environmental parameters in PG4180.

The obscure finding that a combination of corRP from PG4180 and corS from DC3000 gave rise to moderate and temperature-independent cma expression in PG4180, but thermoresponsive expression in DC3000 cannot be explained. Interestingly, the latter result could not be confirmed by respective RT-PCR experiments, suggesting that it might reflect some kind of technical artefact. A similar explanation might be appropriate for the construct in which CorRP and the N-terminal portion of CorS from PG4180 were brought together with the C terminus of CorS from DC3000 and expressed in PG4180.D4.

The most promising result of this study came from the exchange analysis of the $\mathrm{N}$ - and C-terminal domains of CorS in PG4180. Our data suggested a particular role of the $\mathrm{C}$ terminus of this HPK in thermosensing, and furthermore indicated that temperature-mediated $\mathrm{cma}$ expression was most pronounced when the C-terminal part of CorS interacted with CorR of PG4180. Thus, it is tempting to speculate that CorS dimerization or phosphotransfer to CorR via its $\mathrm{C}$ terminus, but not the membrane-embedded $\mathrm{N}$-terminal part of CorS, is involved in the actual temperature-sensing process. However, CorS activity also requires its $\mathrm{N}$ terminus as reported in a previous study (Smirnova \& Ullrich, 2004). To our knowledge, this is the first report of a potential role of the $\mathrm{C}$ terminus in temperature sensing for one of the three well-studied bacterial, low-temperature-sensing HPKs, CorS of $P$. syringae, DesK of Bacillus subtilis (Aguilar et al., 2001), and DspA (Hik33) of Synechocystis sp. PCC 6803 (Suzuki et al., 2000; Inaba et al., 2003). All three kinases differ significantly in their primary amino acid sequences and secondary structures. Hunger et al. (2004) and Albanesi et al. (2004) demonstrated an involvement of the $\mathrm{N}$ terminal membrane-embedded domain of DesK in thermosensing, but no such studies have thus far been conducted with DspA. However, the divergence of these findings from ours could be explained by the fact that DesK controls the saturation level of phospholipids in the membrane of $B$. subtilis and thus is likely to sense changes in the membrane, while CorS controls synthesis of a virulence-associated secondary metabolite in $P$. syringae, which in fact might be embedded in other regulatory circuits.

Future studies will focus on the in-depth analysis of the molecular interactions taking place in the CorRSP system, i.e. CorS dimerization and phosphotransfer reactions, as well as in planta COR gene expression analysis in both PG4180 and DC3000, with variable CorRSP combinations, using a novel in planta bacterial mRNA quantification technique recently developed in our laboratory (Schenk et al., 2008).

\section{ACKNOWLEDGEMENTS}

This work was supported by grants from the Deutsche Forschungsgemeinschaft. We are grateful to Carol Bender and Annette Wensing for stimulating discussions and to Bellinda Schneider for valuable technical assistance.

\section{REFERENCES}

Aguilar, P. S., Hernandez-Arriaga, A. M., Cybulski, L. E., Erazo, A. C. \& de Mendoza, D. (2001). Molecular basis of thermosensing: a twocomponent signal transduction thermometer in Bacillus subtilis. EMBO J 20, 1681-1691.

Alarcon-Chaidez, F. J., Keith, L., Zhao, Y. \& Bender, C. L. (2003). RpoN ( $\sigma 54)$ is required for plasmid-encoded coronatine biosynthesis in Pseudomonas syringae. Plasmid 49, 106-117.

Albanesi, D., Mansilla, M. C. \& de Mendoza, D. (2004). The membrane fluidity sensor DesK of Bacillus subtilis controls the signal decay of its cognate response regulator. J Bacteriol 186, 2655-2663.

Bender, C. L., Malvick, D. K. \& Mitchell, R. E. (1989). Plasmidmediated production of the phytotoxin coronatine in Pseudomonas syringae pv. tomato. J Bacteriol 171, 807-812.

Bender, C. L., Liyanage, H., Palmer, D., Ullrich, M., Young, S. \& Mitchell, R. (1993). Characterization of the genes controlling the biosynthesis of the polyketide phytotoxin coronatine including conjugation between coronafacic and coronamic acid. Gene 133, 31-38.

Bender, C. L., Palmer, D., Peñaloza-Vázquez, A., Rangaswamy, V. \& Ullrich, M. (1996). Biosynthesis of coronatine, a thermoregulated phytotoxin produced by the phytopathogen Pseudomonas syringae. Arch Microbiol 166, 71-75.

Bradford, M. M. (1976). A rapid and sensitive method for quantitation of microgram quantities of protein utilizing the principle of proteindye binding. Anal Biochem 72, 248-254.

Brooks, D. M., Hernández-Guzmán, G., Kloek, A. P., AlarcónChaidez, F., Sreedharan, A., Rangaswamy, V., Peñaloza-Vázquez, A., Bender, C. L. \& Kunkel, B. N. (2004). Identification and characterization of a well-defined series of coronatine biosynthetic mutants of Pseudomonas syringae pv. tomato DC3000. Mol Plant Microbe Interact 17, 162-174.

Budde, I. P., Rohde, B. H., Bender, C. L. \& Ullrich, M. S. (1998). Growth phase and temperature influence promoter activity, transcript abundance, and protein stability during biosynthesis of the Pseudomonas syringae phytotoxin coronatine. J Bacteriol 180, 13601367.

Buell, C. R., Joardar, V., Lindeberg, M., Selengut, J., Paulsen, I. T., Gwinn, M. L., Dodson, R. J., Deboy, R. T., Scott Durkin, A. \& other authors (2003). The complete genome sequence of the Arabidopsis and tomato pathogen Pseudomonas syringae pv. tomato DC3000. Proc Natl Acad Sci U S A 100, 10181-10186.

Cintas, N. A., Koike, S. T. \& Bull, C. T. (2002). A new pathovar, Pseudomonas syringae pv. alisalensis pv. nov., proposed for the causal agent of bacterial blight of broccoli and broccoli raab. Plant Dis 86, 992-998.

Couch, R., O’Connor, S. E., Seidle, H., Walsh, C. T. \& Parry, R. (2004). Characterization of $\mathrm{CmaA}$, an adenylation-thiolation didomain enzyme involved in the biosynthesis of coronatine. J Bacteriol 186, 35-42.

Cuppels, D. A. (1986). Generation and characterization of $\operatorname{Tn} 5$ insertion mutations in Pseudomonas syringae pv. tomato. Appl Environ Microbiol 51, 323-327. 
Figurski, D. H. \& Helinski, D. R. (1979). Replication of an origincontaining derivative of plasmid RK2 dependent on a plasmid function provided in trans. Proc Natl Acad Sci U S A 76, 1648-1652.

Fouts, D. E., Abramovitch, R. B., Alfano, J. R., Baldo, A. M., Buell, C. R., Cartinhour, S., Chatterjee, A. K., D’Ascenzo, M., Gwinn, M. L. \& other authors (2002). Genomewide identification of Pseudomonas syringae pv. tomato DC3000 promoters controlled by the HrpL alternative sigma factor. Proc Natl Acad Sci U S A 99, 2275-2280.

Grebe, T. W. \& Stock, J. B. (1999). The histidine protein kinase superfamily. Adv Microb Physiol 41, 139-227.

Hunger, K., Beckering, C. L. \& Marahiel, M. A. (2004). Genetic evidence for the temperature-sensing ability of the membrane domain of the Bacillus subtilis histidine kinase DesK. FEMS Microbiol Lett 230, $41-46$.

Inaba, M., Suzuki, I., Szalontai, B., Kanesaki, Y., Los, D. A., Hayashi, H. \& Murata, N. (2003). Gene-engineered rigidification of membrane lipids enhances the cold inducibility of gene expression in Synechocystis. J Biol Chem 278, 12191-12198.

Keane, P. J., Kerr, A. \& New, P. B. (1970). Crown gall of stone fruit. II. Identification and nomenclature of Agrobacterium isolates. Aust J Biol Sci 23, 585-595.

Keen, N. T., Tamaki, S., Kobayashi, D. \& Trollinger, D. (1988). Improved broad-host-range plasmids for DNA cloning in Gramnegative bacteria. Gene 70, 191-197.

Koike, S. T., Barak, J. D., Henderson, D. M. \& Gilbertson, R. L. (1999). Bacterial blight of leek: a new disease in California caused by Pseudomonas syringae. Plant Dis 83, 165-170.

Kustu, S., Santero, E., Keener, J., Popham, D. \& Weiss, D. (1989). Expression of sigma 54 ( $n$ trA)-dependent genes is probably united by a common mechanism. Microbiol Rev 53, 367-376.

Liyanage, H., Palmer, D. A., Ullrich, M. \& Bender, C. L. (1995a). Characterization and transcriptional analysis of the gene cluster for coronafacic acid, the polyketide component of the phytotoxin coronatine. Appl Environ Microbiol 61, 3843-3848.

Liyanage, H., Penfold, C., Turner, J. \& Bender, C. L. (1995b). Sequence, expression and transcriptional analysis of the coronafacate ligase-encoding gene required for coronatine biosynthesis by Pseudomonas syringae. Gene 153, 17-23.

Mitchell, R. E. (1982). Coronatine production by some phytopathogenic pseudomonads. Physiol Plant Pathol 20, 83-89.

Mitchell, R. E., Young, S. A. \& Bender, C. L. (1994). Coronamic acid, an intermediate in coronatine biosynthesis by Pseudomonas syringae. Phytochemistry 35, 343-348.

Murillo, J., Shen, H., Gerhold, D., Sharma, A., Cooksey, D. A. \& Keen, N. T. (1994). Characterization of pPT23B, the plasmid involved in syringolide production by Pseudomonas syringae pv. tomato PT23. Plasmid 31, 275-287.

Palmer, D. A. \& Bender, C. L. (1993). Effects of environmental and nutritional factors on production of the polyketide phytotoxin coronatine by Pseudomonas syringae pv. glycinea. Appl Environ Microbiol 59, 1619-1626.

Parry, R. J., Mhaskar, S. V., Lin, M. T., Walker, A. E. \& Mafoti, R. (1994). Investigations of the biosynthesis of the phytotoxin coronatine. Can $\mathrm{J}$ Chem 72, 86-99.

Peñaloza-Vázquez, A. \& Bender, C. L. (1998). Characterization of CorR, a transcriptional activator which is required for biosynthesis of the phytotoxin coronatine. J Bacteriol 180, 6252-6259.
Rangaswamy, V. \& Bender, C. L. (2000). Phosphorylation of CorS and CorR, regulatory proteins that modulate production of the phytotoxin coronatine in Pseudomonas syringae. FEMS Microbiol Lett 193, 13-18.

Rangaswamy, V., Jiralerspong, S., Parry, R. \& Bender, C. L. (1998). Biosynthesis of the Pseudomonas polyketide coronafacic acid requires monofunctional and multifunctional polyketide synthase proteins. Proc Natl Acad Sci U S A 95, 15469-15474.

Sambrook, J. \& Russell, D. W. (2001). Molecular Cloning: a Laboratory Manual, 3rd edn. Cold Spring Harbor, NY: Cold Spring Harbor Laboratory.

Schenk, A., Weingart, H. \& Ullrich, M. S. (2008). Extraction of highquality bacterial RNA from infected leaf tissue for bacterial in planta gene expression analysis by multiplexed fluorescent Northern hybridization. Mol Plant Pathol 9, 227-235.

Smirnova, A. V. \& Ullich, M. S. (2004). Topological and deletion analysis of CorS, a Pseudomonas syringae sensor kinase. Microbiology 150, 2715-2726.

Smirnova, A. V., Braun, Y. \& Ullrich, M. S. (2008). Site-directed mutagenesis of the temperature-sensing histidine protein kinase CorS from Pseudomonas syringae. FEMS Microbiol Lett 283, 231-238.

Sreedharan, A., Peñaloza-Vázquez, A., Kunkel, B. N. \& Bender, C. L. (2006). CorR regulates multiple components of virulence in Pseudomonas syringae pv. tomato DC3000. Mol Plant Microbe Interact 19, 768-779.

Studholme, D. J. \& Buck, M. (2000). The biology of enhancerdependent transcriptional regulation in bacteria: insights from genome sequences. FEMS Microbiol Lett 186, 1-9.

Suzuki, I., Los, A. D., Kanesaki, Yu., Mikami, K. \& Murata, N. (2000). The pathway for perception and transduction of low-temperature signals in Synechocystis. EMBO J 19, 1327-1334.

Ullrich, M. \& Bender, C. L. (1994). The biosynthetic gene cluster for coronamic acid, an ethylcyclopropyl amino acid, contains genes homologous to amino acid-activating enzymes and thioesterases. $J$ Bacteriol 176, 7574-7586.

Ullrich, M., Peñaloza-Vázquez, A., Bailey, A. M. \& Bender, C. L. (1995). A modified two-component regulatory system is involved in temperature-dependent biosynthesis of the Pseudomonas syringae phytotoxin coronatine. J Bacteriol 177, 6160-6169.

Völksch, B. \& Weingart, H. (1998). Toxin production by pathovars of Pseudomonas syringae and their antagonistic activities against epiphytic microorganisms. J Basic Microbiol 38, 135-145.

Wang, L., Bender, C. L. \& Ullrich, M. S. (1999). The transcriptional activator CorR is involved in biosynthesis of the phytotoxin coronatine and binds to the cmaABT promoter region in a temperature-dependent manner. Mol Gen Genet 262, 250-260.

Weingart, H., Stubner, S., Schenk, A. \& Ullrich, M. S. (2004). Impact of temperature on in planta expression of genes involved in synthesis of the Pseudomonas syringae phytotoxin coronatine. Mol Plant Microbe Interact 17, 1095-1102.

Wösten, M. M. S. M. (1998). Eubacterial sigma-factors. FEMS Microbiol Rev 22, 127-150.

Zhao, Y. F., Damicone, J. P. \& Bender, C. L. (2002). Detection, survival, and sources of inoculum for bacterial diseases of leafy crucifers in Oklahoma. Plant Dis 86, 883-888.

Edited by: I. K. Toth 